\title{
Phase Separation in Rapid Solidified Ag-rich Ag-Cu-Zr Alloys
}

\author{
Saisamorn Niyomsoan ${ }^{a, b}$, Piter Gargarella ${ }^{b, c}$, Natthaphol Chomsaeng ${ }^{a}$, Preecha Termsuksawad $^{d}$, \\ Utha Kühn ${ }^{b}$, Jürgen Eckert ${ }^{b}$ \\ a Jewelry Materials Research and Development Center, Faculty of Gems, \\ Burapha University, Chanthaburi 22170, Thailand \\ ${ }^{b}$ IFW Dresden, Institut für Komplexe Materialien, Helmholtzstraße 20, D-01069, Dresden, Germany \\ 'Departamento de Engenharia de Materiais, Universidade Federal de São Carlos, \\ Rod. Washington Luis, Km 235, CEP 13565-905, São Carlos, SP, Brazil \\ ${ }^{d}$ School of Energy, Environment and Materials, King Mongkut's University of Technology Thonburi, \\ Bangkok 10140, Thailand
}

Received: September 30, 2014; Revised: October 6, 2015

\begin{abstract}
The microstructure and phase formation of rapid solidified Ag-rich Ag-Cu-Zr alloys were investigated. Two types of structure; interconnected- and droplet-type structures, were obtained due to phase separation mechanisms. The former was spinodal decomposition and the later was nucleation and growth mechanism. Depending on the alloy compositions, three crystalline phases; FCC-Ag, $\mathrm{AgZr}$ and $\mathrm{Cu}_{10} \mathrm{Zr}_{7}$ phases were observed along with an in-situ nanocrystalline/amorphous composite. Vickers hardness testing indicated a significant increase of hardness in the nanocrystalline/amorphouscomposite alloy.
\end{abstract}

Keywords: phase separation, rapid solidification, Ag-rich alloys

\section{Introduction}

Within the past decade, there were several reports about phase separation in the rapid solidified Ag-Cu-Zr system. Kundig et al. ${ }^{1}$ revealed a miscibility gap of a liquid phase in the Ag-rich region. Phase separation was predicted due to the positive enthalpy of mixing of $\mathrm{Cu}-\mathrm{Ag}\left(10.8 \mathrm{~kJ} \cdot \mathrm{mol}^{-1}\right)$ and negative enthalpies of mixing of both $\mathrm{Ag}-\mathrm{Zr}$ and $\mathrm{Cu}-\mathrm{Zr}$ $\left(-20 \mathrm{~kJ} \cdot \mathrm{mol}^{-1} \text { and }-23 \mathrm{~kJ} \cdot \mathrm{mol}^{-1} \text {, respectively }\right)^{2}$. Kang \& Jung ${ }^{3}$ reported a complete prediction of the $\mathrm{Cu}-\mathrm{Zr}-\mathrm{Ag}$ system based on thermodynamic calculation. The prediction indicates an area of miscibility gap with spinodal decomposition where the Ag-rich nanocrystalline particles are formed in an amorphous matrix up to 90 at.\% of Ag content. However, a few evidences have been reported on the liquid phase separation of the $\mathrm{Ag}-\mathrm{Cu}-\mathrm{Zr}$ system in the Ag-rich area. Janovszky et al. ${ }^{4}$ described microstructural evolution of the liquid phase separation in the $\mathrm{Ag}-\mathrm{Cu}-\mathrm{Zr}$ system up to 70 at.\% of $\mathrm{Ag}$ content. Castellero et al. ${ }^{5}$ reviewed liquid miscibility gap in the melt- spun $\mathrm{Ag}-\mathrm{Cu}-\mathrm{Zr}$ system at 73 at.\% of Ag content.

Several factors may influence the microstructural evolution of phase-separated glass; a critical temperature, compositional range in the miscibility gap, symmetry of the spinodal curve, glass-forming ability of the liquid, and

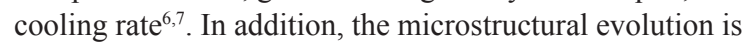
influenced by viscosity and diffusivity of the melt ${ }^{8}$. Size of the phase-separated structure also depends on time interval between an onset of the phase separation and completion of the solidification ${ }^{9}$. The boundaries of the liquid ternary

*e-mail: sniyomsoan@gmail.com, saisamor@buu.ac.th miscibility gap can also be enlarged by applying high cooling rates ${ }^{7}$.

Basically, two types of structures are observed in liquid-liquid phase separation owing to different separation mechanisms: interconnected-type structure due to spinodal decomposition, and droplet-type structure due to the nucleation and growth mechanism ${ }^{6}$. Park et al. ${ }^{10}$ clearly showed that the interconnected-type or droplet-type structure depends on the alloys composition in the miscibility gap. According to the glass-forming ability of the separated liquid phases, an amorphous/amorphous or amorphous/crystalline structure can be obtained as composite structures ${ }^{6,10,11}$. The phase separating mechanisms provide a unique opportunity for designing composite materials with hierarchical microstructure at different length scales.

The present study focused on investigating the microstructure and phase formation of the melt-spun Ag-rich Ag-Cu- $\mathrm{Zr}$ system up to 80 at. $\%$ of Ag content. Microstructural evolution of phase separation was studied using XRD, DSC, SEM and TEM including Vickers micro-hardness tester.

\section{Experimental}

$\mathrm{Ag}_{100-2 \mathrm{x}} \mathrm{Cu}_{\mathrm{x}} \mathrm{Zr}_{\mathrm{x}}$ alloys, where $\mathrm{x}=10,15$ and 20, were prepared with high-purity starting elements (99.99\% purity or higher). Ingots were melted in a water-cooled copper crucible under a Ti-gettered argon atmosphere. The alloys were re-melted at least four times in the same furnace to ensure chemical homogeneity.

Rapidly solidified ribbons were prepared in a single roller melt-spinner in Ar atmosphere by remelting each ingot in 
a quartz tube and then ejecting it through a nozzle onto a spinning $\mathrm{Cu}$ wheel. Melt spinning was performed at $30 \mathrm{~ms}^{-1}$ wheel speed. The ribbons then experienced high cooling rate of approximately $6.9 \times 10^{6} \mathrm{~K} \cdot \mathrm{s}^{-1[12]}$. An ejection temperature of the ribbons was $1273 \mathrm{~K}$ and an ejection pressure was around $50 \mathrm{MPa}$. An approximate width and thickness of the melt-spun ribbons were $5 \mathrm{~mm}$ and $50 \mu \mathrm{m}$, respectively.

The structure of the ribbons was characterized using X-ray diffraction (XRD) on a STOE STADI P diffractometer in transmission geometry (Bragg-Brentano) and equipped with a Co-source (monochromatic radiation, $\lambda_{\mathrm{K} \alpha}=1.789 \AA$ ). The microstructure was analysed using FEI Nova Nano SEM 450 scanning electron microscope (SEM) in backscattered mode. The composition of different phases was confirmed using a Bruker Xflash 6/30 energy-dispersive X-ray spectrometer (EDX) attached to the SEM. An experimental detection limit of the EDX measurement was around 0.1 at. $\%{ }^{[13]}$. The thermal stability was studied by differential scanning calorimetry (DSC) at a heating rate of $30 \mathrm{~K} / \mathrm{min}$ in a Perkin-Elmer differential scanning calorimeter (DSC-7). The measurements were carried out in an argon atmosphere ranging from $298 \mathrm{~K}$ to $923 \mathrm{~K}$.

Fine microstructural features in the $\mathrm{Ag}-\mathrm{Cu}-\mathrm{Zr}$ ribbons were further analysed by transmission electron microscopy (TEM). Thin foils of these samples were examined using a JEOL JEM-2010 transmission electron microscope, operating at $200 \mathrm{kV}$. The sample preparation for TEM analysis was finished by a dimple grinder. Vickers hardness was measured on the ribbon cross section with a load of $10 \mathrm{~g}$ and loading time of $10 \mathrm{~s}$ using a HMV-2000 Microhardness tester SHIMADZU.

\section{Results and Discussion}

XRD patterns of the rapid solidified $\mathrm{Ag}_{100-2 \mathrm{x}} \mathrm{Cu}_{\mathrm{x}} \mathrm{Zr}_{\mathrm{x}}$ ribbons are shown in Figure 1. The analysis indicated FCC-Ag phase in all ribbons. $\mathrm{AgZr}$ and $\mathrm{Cu}_{10} \mathrm{Zr}_{7}$ phases were clearly detected in the ribbons with $10-15$ at. $\%$ of $\mathrm{Cu}-\mathrm{Zr}$ contents. Additionally, the FCC-Ag phase obtained broad XRD peaks indicating nanocrystalline structure.

With 10-15 at.\% of $\mathrm{Cu}$ and $\mathrm{Zr}$ contents, the rapid solidified $\mathrm{Ag}_{100-2 \mathrm{x}} \mathrm{Cu}_{\mathrm{x}} \mathrm{Zr}_{\mathrm{x}}$ ribbons possessed three equilibrium phases; FCC-Ag, $\mathrm{AgZr}$ and $\mathrm{Cu}_{10} \mathrm{Zr}_{7}$, in agreement with the prediction reported by Castellero et al. ${ }^{5}$. Phase transformation of the Ag-rich $\mathrm{Ag}-\mathrm{Cu}-\mathrm{Zr}$ compositions went through many isothermal reactions as follows ${ }^{5}$ :

$L \rightarrow L_{1}+L_{2}$

Liquid phase separation

$L_{1}+L_{2} \rightarrow L_{1}^{\prime}+L_{2}^{\prime}+\mathrm{AgZr} \quad$ Primary precipitation

$$
\begin{aligned}
& L_{1}^{\prime}(\text { Ag-rich }) \rightarrow L_{2}^{\prime}(\text { Ag-poor })+ \\
& \text { AgZr }+ \text { fcc- } \mathrm{Ag} \\
& \text { Monotectic reaction }
\end{aligned}
$$

$L_{2}^{\prime}+\mathrm{fcc}-\mathrm{Ag} \rightarrow \mathrm{AgZr}+\mathrm{AgCu} 4 \mathrm{Zr} \quad$ Peritectic reaction (4)

$\mathrm{AgZr}+\mathrm{AgCu}_{4} \mathrm{Zr} \rightarrow \mathrm{Cu}_{10} \mathrm{Zr}_{7}+$ fcc-Ag Peritectiod reaction (5)

According to the reaction sequences, phase formation of the $\mathrm{Ag}_{70} \mathrm{Cu}_{15} \mathrm{Zr}_{15}$ and $\mathrm{Ag}_{80} \mathrm{Cu}_{10} \mathrm{Zr}_{10}$ alloys started from liquid phase separation with a precipitation of $\mathrm{AgZr}$ phase. Subsequently, the monotectic, peritectic and, finally, peritectiod reactions leaded to the presence of three equilibrium phases. Consequently, the $\mathrm{AgCu}_{4} \mathrm{Zr}$ phase might be formed by the peritectic reaction and then, in this study, completely transformed into $\mathrm{Cu}_{10} \mathrm{Zr}_{7}$ phase by the peritectoid reaction above $873 \mathrm{~K}^{[5]}$. However, the same sequence was not applicable with the phase formation in the $\mathrm{Ag}_{60} \mathrm{Cu}_{20} \mathrm{Zr}_{20}$ ribbons.

Figure 2 shows the DSC result for the $\mathrm{Ag}_{60} \mathrm{Cu}_{20} \mathrm{Zr}_{20}$ ribbon at a heating rate of $30 \mathrm{~K} / \mathrm{min}$. Three typical events of a rapid solidified sample could be clearly observed: relaxation, glass transition and crystallization. The relaxation occurred with an onset relaxation temperature $\left(\mathrm{T}_{\mathrm{r}}\right)$ at $568 \pm 2 \mathrm{~K}$. The glass transition $\left(\mathrm{T}_{\mathrm{g}}\right)$ was observed at $665 \pm 2 \mathrm{~K}$ followed by two exothermic crystallization peaks with an onset crystallization temperature $\left(\mathrm{T}_{\mathrm{x}}\right)$ at $707 \pm 2 \mathrm{~K}$. However, these temperatures depend on the cooling rate ${ }^{14}$. The DSC analysis proved the presence of a glassy phase in the $\mathrm{Ag}_{60} \mathrm{Cu}_{20} \mathrm{Zr}_{20}$ ribbon.

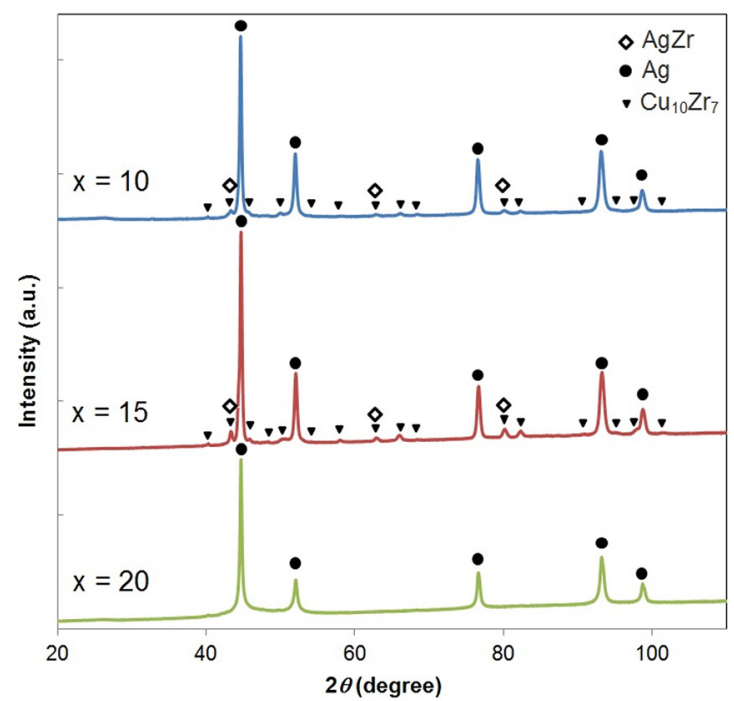

Figure 1. XRD patterns of the melt-spun $\mathrm{Ag}_{100-2 \mathrm{x}} \mathrm{Cu}_{\mathrm{x}} \mathrm{Zr}_{\mathrm{x}}$ samples, where $\mathrm{x}=10,15$ and 20 .

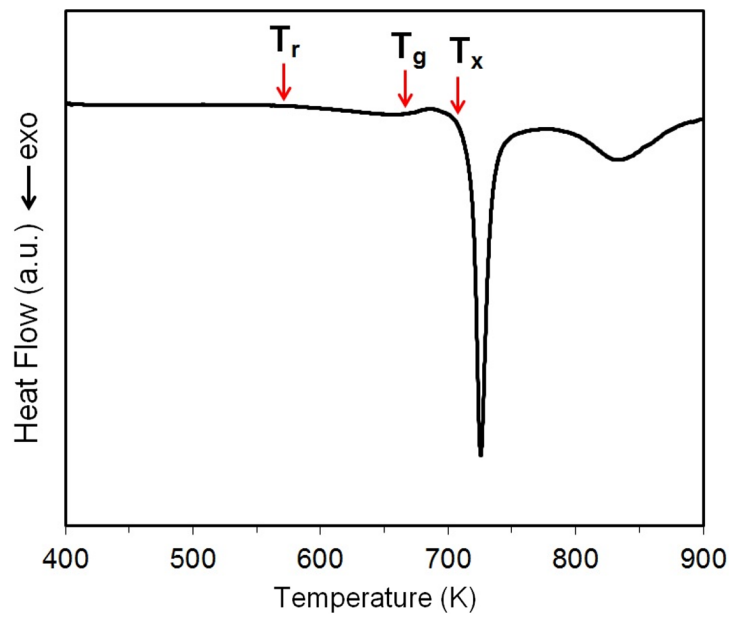

Figure 2. DSC results of the melt-spun $\mathrm{Ag}_{60} \mathrm{Cu}_{20} \mathrm{Zr}_{20}$ ribbon (at $30 \mathrm{~K} / \mathrm{min}$ heating rate). 
Combining the DSC and XRD results, it was possible to confirm the presence of the glassy phase with nanocrystalline FCC-Ag phase in the melt-spun $\mathrm{Ag}_{60} \mathrm{Cu}_{20} \mathrm{Zr}_{20}$ system.

The microstructure of the rapid-solidified $\mathrm{Ag}_{100-2 \mathrm{x}} \mathrm{Cu}_{\mathrm{x}} \mathrm{Zr}_{\mathrm{x}}$ ribbons, where $x=10,15$ and 20, was investigated by SEM and the results are shown in Figure 3 and Figure 4. A liquid-like phase distribution in all ribbons revealed that phase separation performed in the liquid state. In the ribbons with $10-15$ at. $\% \mathrm{Cu}$ and $\mathrm{Zr}$ contents, primary phase separation occurred through the spinodal decomposition mechanism. As the $\mathrm{Cu}$ and $\mathrm{Zr}$ contents reached 20 at. \%, the primary phase was separated by the nucleation and growth mechanism. Multi-step phase separation was also observed in the $\mathrm{Ag}_{60} \mathrm{Cu}_{20} \mathrm{Zr}_{20}$ and $\mathrm{Ag}_{70} \mathrm{Cu}_{15} \mathrm{Zr}_{15}$ ribbons especially at the free surface.
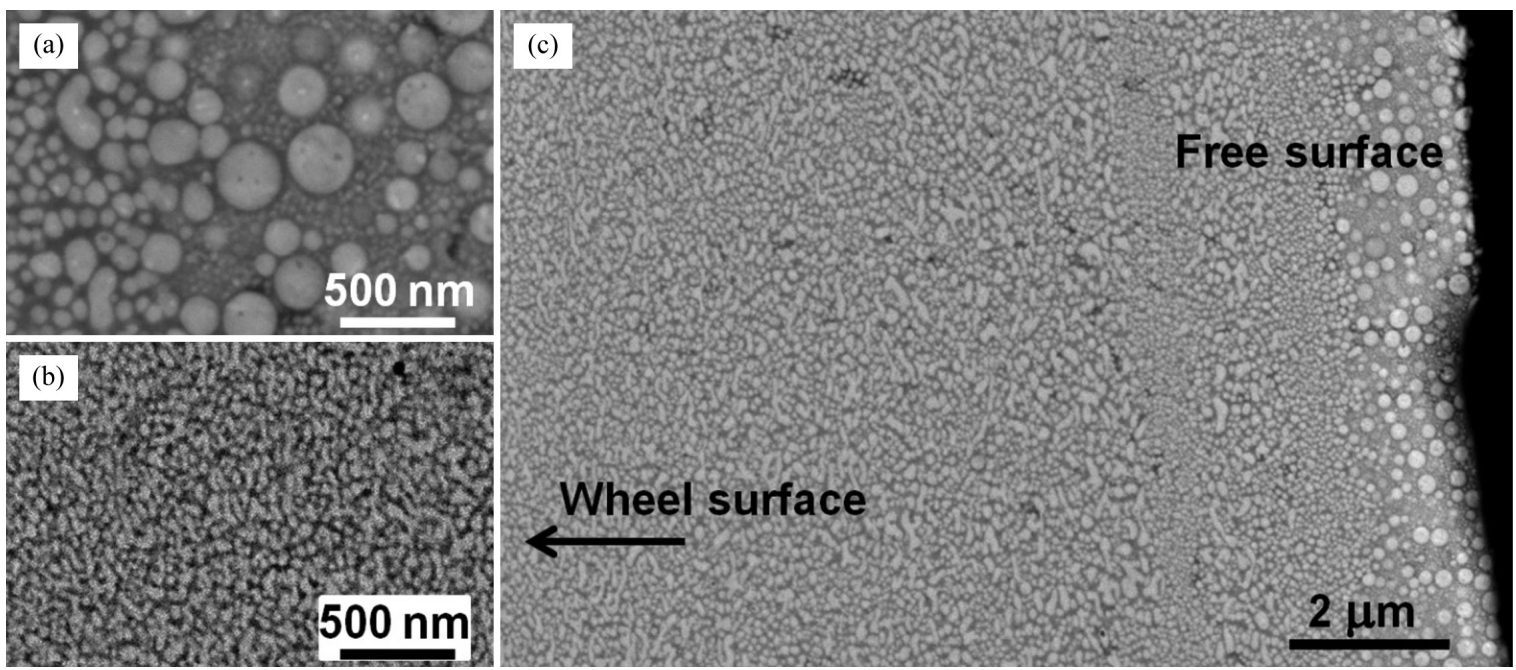

Figure 3. SEM image of the melt-spun $\mathrm{Ag}_{60} \mathrm{Cu}_{20} \mathrm{Zr}_{20}$ ribbon. (a) free surface, (b) wheel surface and (c) cross-section view of the ribbon. The ribbon ejection temperature was $1273 \mathrm{~K}$.

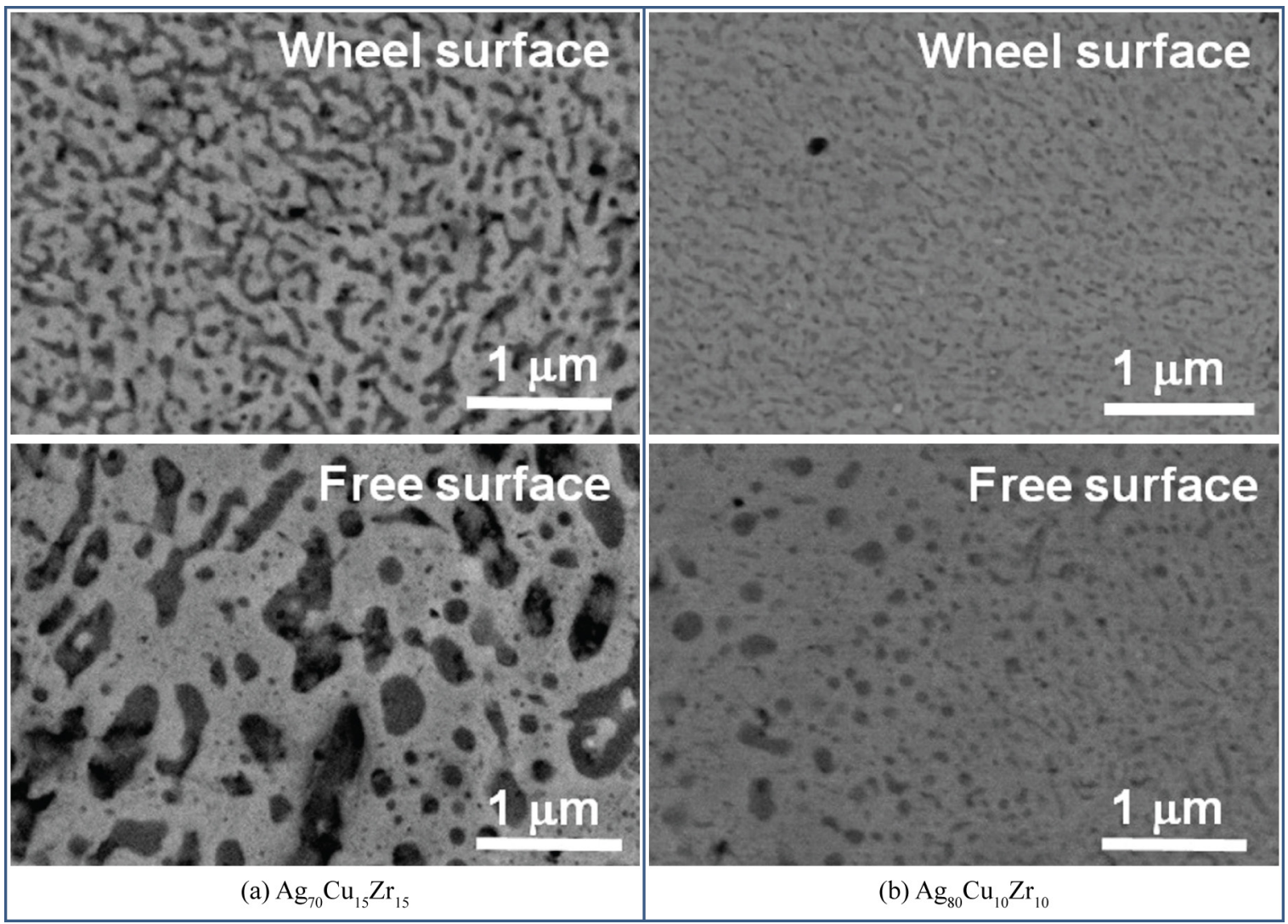

Figure 4. SEM image of the melt-spun ribbons. (a) $\mathrm{Ag}_{70} \mathrm{Cu}_{15} \mathrm{Zr}_{15}$ and (b) $\mathrm{Ag}_{80} \mathrm{Cu}_{10} \mathrm{Zr}_{10}$. 
The microstructure of the melt-spun $\mathrm{Ag}_{60} \mathrm{Cu}_{20} \mathrm{Zr}_{20}$ ribbons consisted of a bright liquid-like phase distributed among a dark matrix (Figure 3). The bright and dark phases corresponded with the Ag-rich phase and $\mathrm{Cu}-\mathrm{Zr}$-rich phase (or Ag-poor phase), respectively, according to the backscattered microscopy and EDX measurements. Dispersion of droplets of the Ag-rich liquid in the $\mathrm{Cu}-\mathrm{Zr}$-rich liquid indicated that volume fraction of the Ag-rich phase in the ribbon was less than 50 vol. $\%{ }^{[7]}$.

Different sizes and morphologies of the melt-spun $\mathrm{Ag}_{60} \mathrm{Cu}_{20} \mathrm{Zr}_{20}$ ribbon changed across thickness of the ribbon. Cooling rate increased as going from the free surface to the wheel surface of the ribbon. Consequently, the spherical droplet-type structure and fine irregular droplet structure were observed as shown in Figure $3 \mathrm{a}$ and $\mathrm{b}$. Fast heat transfer from the melt to the spinning $\mathrm{Cu}$ wheel provided an extremely high driving force for nucleation. Approximately 50-100 nm-size spherical droplets were formed at the free surface of the ribbon and there were also many droplets below $50 \mathrm{~nm}$. At the wheel side, the droplets were averagely smaller than $50 \mathrm{~nm}$, reviewing that this part of the ribbon experienced higher cooling rate.

At the free surface of the $\mathrm{Ag}_{60} \mathrm{Cu}_{20} \mathrm{Zr}_{20}$ ribbons, the multi-step phase separation was clearly observed (Figure $3 \mathrm{a}$ ). As a result of the second phase separation during further cooling, the small internal droplets appeared within the large droplets as so called a marble-type structure ${ }^{15}$. From their microstructural morphology, the primary and secondary phase separation mechanisms were identified as the nucleation and growth process ${ }^{6,9}$.

SEM images of the melt-spun $\mathrm{Ag}_{70} \mathrm{Cu}_{15} \mathrm{Zr}_{15}$ and $\mathrm{Ag}_{80} \mathrm{Cu}_{10} \mathrm{Zr}_{10}$ ribbons were shown in Figure $4 \mathrm{a}$ and $\mathrm{b}$, respectively. The interconnected structure of the bright region (Ag-rich phase) and the dark region ( $\mathrm{Cu}-\mathrm{Zr}$-rich phase) was observed in both ribbons. The experimental observation of the interconnected microstructure implied that the liquid phase separation occurred with the spinodal decomposition mechanism ${ }^{6}$. The interconnected structure of the Ag-rich and $\mathrm{Cu}-\mathrm{Zr}$-rich phases revealed an approximately equal volume fraction of the two phases in the $\mathrm{Ag}_{70} \mathrm{Cu}_{15} \mathrm{Zr}_{15}$ ribbon ${ }^{7}$. However, in the $\mathrm{Ag}_{80} \mathrm{Cu}_{10} \mathrm{Zr}_{10}$ ribbon, a smaller scale of the interconnected $\mathrm{Cu}-\mathrm{Zr}$-rich phase indicated a lower volume fraction of the $\mathrm{Cu}-\mathrm{Zr}$-rich phase than that of the Ag-rich phase.

The multi-step phase separation was obviously presented at the free surface of both melt-spun $\mathrm{Ag}_{70} \mathrm{Cu}_{15} \mathrm{Zr}_{15}$ and $\mathrm{Ag}_{80} \mathrm{Cu}_{10} \mathrm{Zr}_{10}$ ribbons (Figure 4). Small internal droplets were formed as the secondary separated phases inside the interconnected structures. The droplet morphology indicated the secondary phase separation mechanism as the nucleation and growth process ${ }^{6}$. The same multi-step phase separation mechanism was also reported by Janovszky et al. ${ }^{7}$ in the $\mathrm{Ag}_{70} \mathrm{Cu}_{15} \mathrm{Zr}_{15}$ alloys prepared at lower cooling rate varying from $2000 \mathrm{~K} . \mathrm{s}^{-1}$ to $20000 \mathrm{~K} . \mathrm{s}^{-1}$.

The current experimental observation showed that the melts of the $\mathrm{Ag}_{100-2 \mathrm{x}} \mathrm{Cu}_{\mathrm{x}} \mathrm{Zr}_{\mathrm{x}}$ alloys, where $\mathrm{x}=10,15$ and 20 , were rapidly cooled into the miscibility gap and then decomposed into two distinct types of structure. The purposed phase separation sequences were schematically drawn in Figure 5 and Figure 6 to describe the structural evolutions regarding works of Ziewiec et al. ${ }^{9}$ and Chang et al. ${ }^{6}$.

Sequence of the marble-type structure development in the $\mathrm{Ag}_{60} \mathrm{Cu}_{20} \mathrm{Zr}_{20}$ ribbon due to the multi-step phase separation during rapid cooling was sketched in Figure 5. An alloy with a starting composition locating in the nucleation region

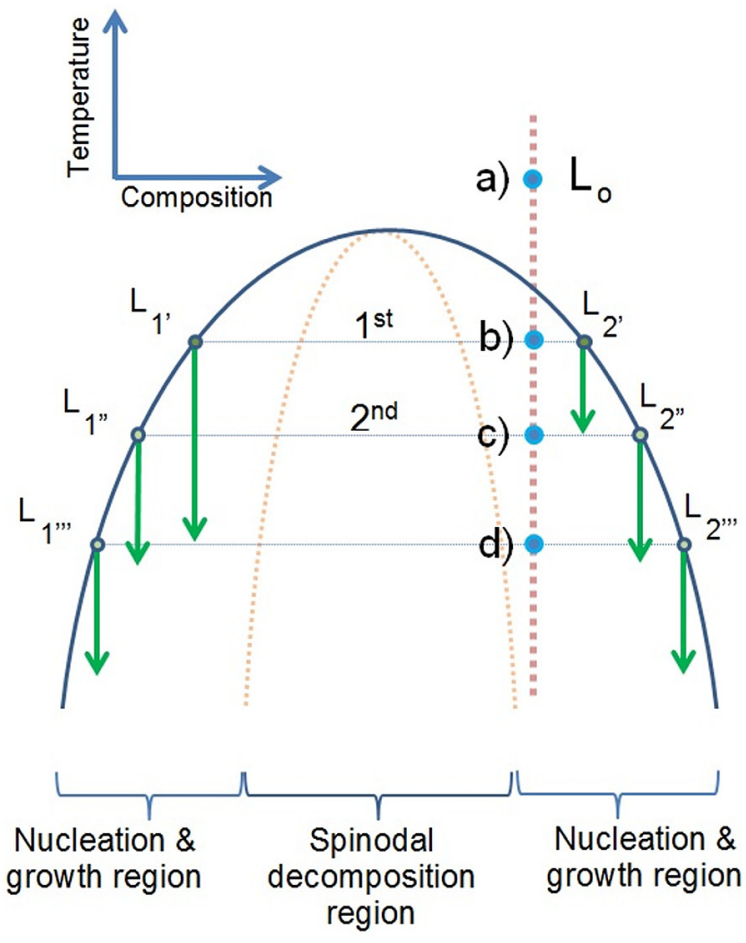

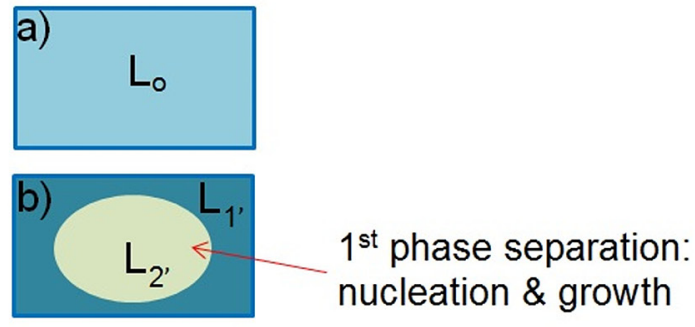

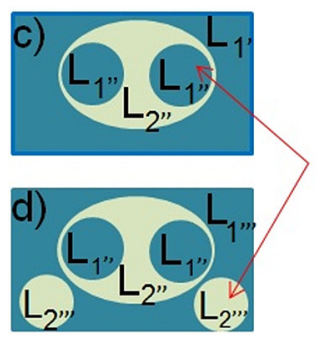

$2^{\text {nd }}$ phase separation: nucleation \& growth

Figure 5. Schematic diagram showing multi-step phase separation sequence and marble structure development. 
within the miscibility gap was cooled down through the critical temperature. At the first separation temperature $\left(\mathrm{T}_{1 \mathrm{st}}\right)$, the primary droplets were separated from the matrix. As the temperature was further reduced, the compositions of each phase became supersaturated within the nucleation region, and then second phase was separated at the second separation temperature $\left(\mathrm{T}_{2 \mathrm{nd}}\right)$. This marble-structure sequence is normal for the starting composition that locates in the nucleation and growth region of the symmetric spinodal curve with relatively small range of spinodal composition ${ }^{6}$.

Sequence of the multi-step structure development in the $\mathrm{Ag}_{70} \mathrm{Cu}_{15} \mathrm{Zr}_{15}$ and $\mathrm{Ag}_{80} \mathrm{Cu}_{10} \mathrm{Zr}_{10}$ ribbons was purposed in Figure 6. The interconnected structure with internal droplets was developed from the starting composition within the spinodal region. During cooling, the primary phase separation took place at the first phase separation temperature $\left(\mathrm{T}_{1 \mathrm{st}}\right)$.
The interconnected structure was generated with the spinodal decomposition mechanism. Consequently, at the second phase separation temperature $\left(\mathrm{T}_{2 \text { d d }}\right)$, the starting compositions located in the nucleation and growth region. Therefore, second phases were separated in the droplet-like structure due to the nucleation and growth mechanism.

TEM results of the melt-spun $\mathrm{Ag}_{60} \mathrm{Cu}_{20} \mathrm{Zr}_{20}$ ribbons prepared at $1273 \mathrm{~K}$ ejection temperature are shown in Figure 7. The bright-field TEM image in Figure 7a reveals spherical droplets of nanocrystalline phase with approximately 5 - 10 nanometers in diameter. Figure $7 \mathrm{~b}$ presents the corresponding selected area diffraction patterns (SADP) of an area encircled in Figure 7a. The diffraction patterns consisted of a broad diffusive ring and several discrete rings which are typical for amorphous and crystalline phases, respectively. The discrete diffraction rings in Figure $7 \mathrm{~b}$ were identified

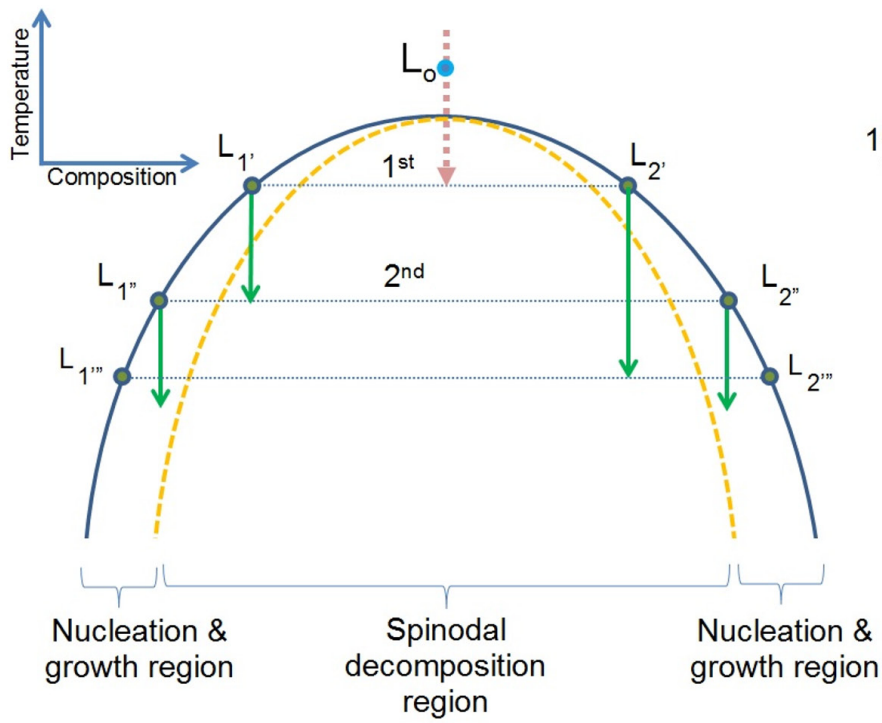

1st phase separation: spinodal decomposition

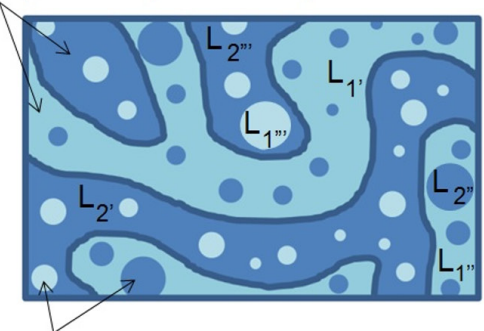

$2^{\text {nd }}$ phase separation: nucleation $\&$ growth

Figure 6. Schematic diagram showing multi-step phase separation sequence and interconnected structure with internal droplets.

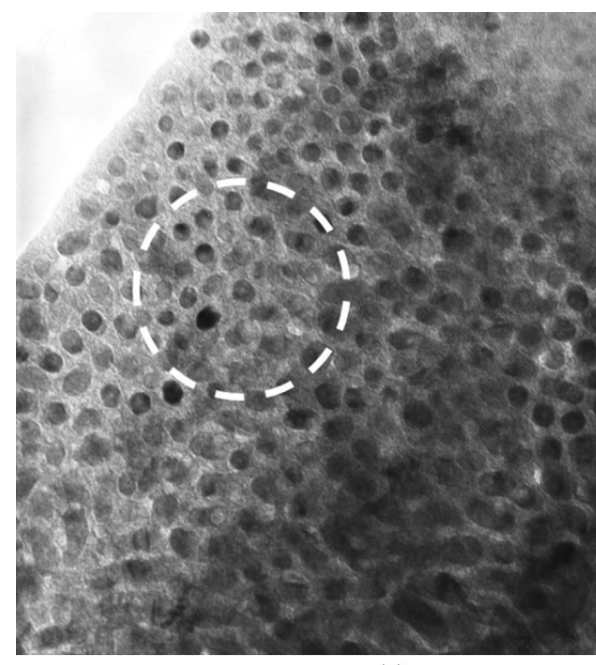

(a)

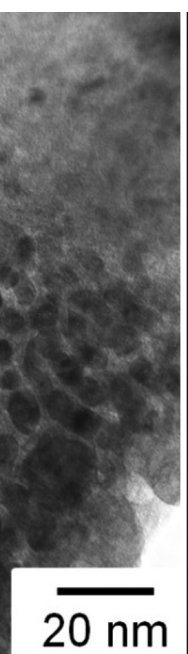

$20 \mathrm{~nm}$

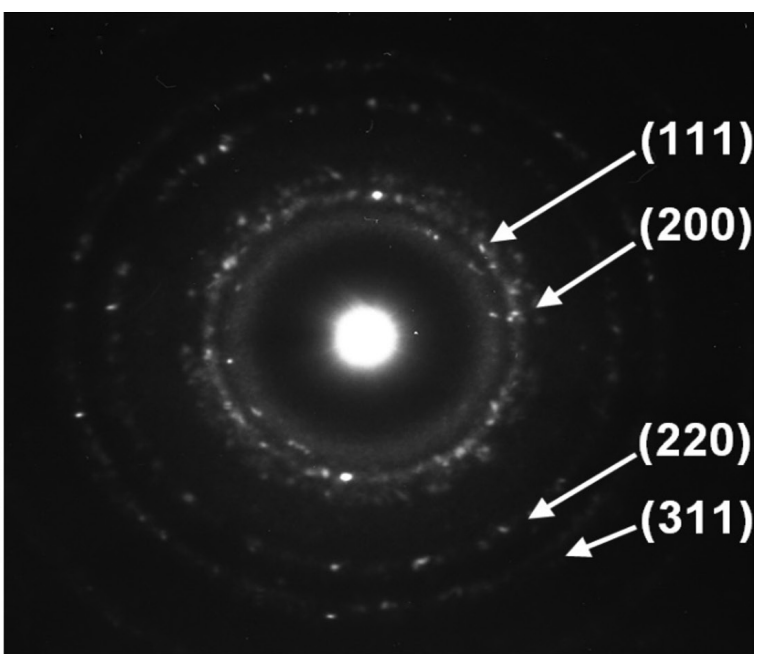

(b)

Figure 7. TEM images of the melt-spun $\mathrm{Ag}_{60} \mathrm{Cu}_{20} \mathrm{Zr}_{20}$ ribbon. (a) BF image and (b) the corresponding SADP of a circle area in (a). 


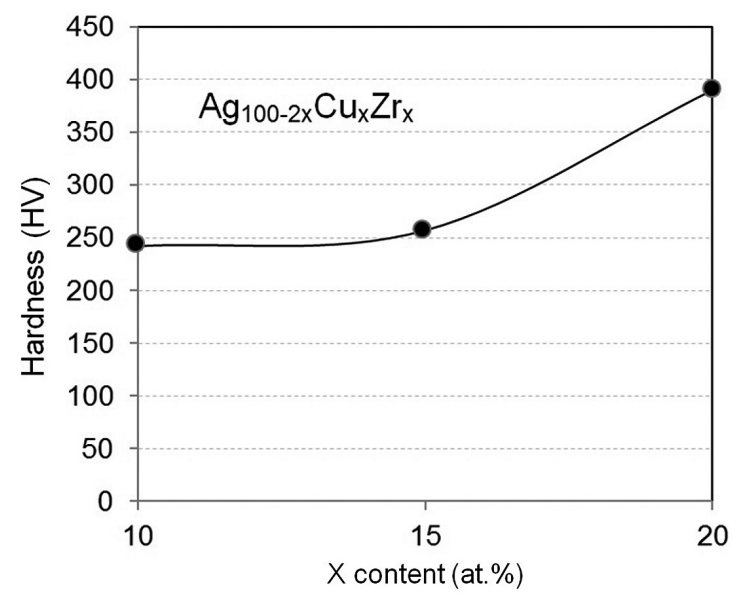

Figure 8. Vickers hardness of $\mathrm{Ag}_{100-2 x} \mathrm{Cu}_{x} \mathrm{Zr}_{x}$ ribbons where $\mathrm{x}=10,15$ and 20 at. $\%$.

as patterns from a group of crystallographic planes of FCCAg; (111), (200), (220) and (311) (Ref. No. 04-002-1170 of ICDD-4+). The TEM results displayed a distribution of the FCC-Ag nanocrystalline particles among the amorphous matrix.

The in-situ nanocrystalline/amorphous composite was clearly observed in the melt-spun $\mathrm{Ag}_{60} \mathrm{Cu}_{20} \mathrm{Zr}_{20}$ ribbons. The presence of amorphous and nanocrystalline phases followed the prediction proposed by Kang \& Jung ${ }^{3}$, which suggests the presence of amorphous phase with the Ag-rich particles in the Ag-rich alloys containing up to 80 at.\% of $\mathrm{Ag}$ content. The amorphous phase was a result of the $\mathrm{Cu}-\mathrm{Zr}$ rich phase (Ag-poor phase) which has high glass forming ability and suppresses the crystallization in the rapid-solidification process. In the $\mathrm{Ag}-\mathrm{Cu}-\mathrm{Zr}$ ternary system studied by Song et al. ${ }^{16}$, the best glass-forming compositions determined experimentally are located in the $\mathrm{Cu}-\mathrm{Zr}$ rich

\section{References}

1. Kundig A, Ohnuma M, Ohkubo T, Abe T and Hono K. Glass formation and phase separation in the $\mathrm{Ag}-\mathrm{Cu}-\mathrm{Zr}$ system. Scripta Materialia. 2006; 55(5):449-452. http://dx.doi.org/10.1016/j. scriptamat.2006.05.012.

2. Boer F, Boom R, Mattens W, Miedema A and Niessen A. Cohesion in metals: transition metal alloys, cohesion and structure. Amsterdam: Elsevier; 1988.

3. Kang D and Jung I-H. Critical thermodynamic evaluation and optimization of the $\mathrm{Ag}-\mathrm{Zr}, \mathrm{Cu}-\mathrm{Zr}$ and $\mathrm{Ag}-\mathrm{Cu}-\mathrm{Zr}$ systems and its applications to amorphous $\mathrm{Cu}-\mathrm{Zr}-\mathrm{Ag}$ alloys. Intermetallics. 2010; 18(5):815-833. http://dx.doi.org/10.1016/j.intermet.2009.12.013.

4. Janovszky D, Tomolya K, Sycheva A and Kaptay G. Stable miscibility gap in liquid $\mathrm{Cu}-\mathrm{Zr}-\mathrm{Ag}$ ternary alloy. Journal of Alloys and Compounds. 2012; 541:353-358. http://dx.doi. org/10.1016/j.jallcom.2012.07.015.

5. Castellero A, Kang D, Jung I-H, Angella G, Vedani M and Baricco M. Rapid solidification of Ag-rich $\mathrm{Ag}-\mathrm{Cu}-\mathrm{Zr}$ alloys. Journal of Alloys and Compounds. 2012; 536S:S148-S153. http://dx.doi.org/10.1016/j.jallcom.2011.12.089.

6. Chang H, Yook W, Park E, Kyeong J and Kim D. Synthesis of metallic glass composites using phase separation phenomena. Acta area and predicted at $\mathrm{Cu}_{59} \mathrm{Zr}_{30} \mathrm{Ag}_{11}$ and $\mathrm{Cu}_{43} \mathrm{Zr}_{41} \mathrm{Ag}_{16}$ with a deviation of 6 at. $\%$.

Vickers hardness of the $\mathrm{Ag}_{100-2 \mathrm{x}} \mathrm{Cu}_{\mathrm{x}} \mathrm{Zr}_{\mathrm{x}}$ ribbons, where $\mathrm{x}=10,15$ and 20, is shown in Figure 8. With increasing $\mathrm{Cu}$ and $\mathrm{Zr}$ contents from 10 to 15 and 20 at.\%, the hardness increased from $242+39$ to $257+54$ and $390+23 \mathrm{HV}$, respectively. The hardness increased with $\mathrm{Cu}-\mathrm{Zr}$ contents and dramatically increased as the content reached 20 at. \% together with the presence of both FCC-Ag nanocrystalline and $\mathrm{Cu}-\mathrm{Zr}$ rich amorphous structure. The nanocrystalline/amorphous composite exhibited excellent mechanical properties as a result of a combination of the high strength glassy phase and the ductile and tough nanocrystalline phase.

\section{Conclusions}

Microstructure of the rapidly solidified Ag-rich Ag-Cu-Zr system was investigated. Liquid phase separation phenomena were experimentally observed in the melt-spun $\mathrm{Ag}_{100-2 \mathrm{x}} \mathrm{Cu}_{\mathrm{x}} \mathrm{Zr}_{\mathrm{x}}$ ribbons containing up to 80 at. $\%$ of Ag content. Depending on the alloys composition, three crystalline phases were formed; FCC-Ag solid solution, $\mathrm{AgZr}$ and $\mathrm{Cu}_{10} \mathrm{Zr}_{7}$ phases. Two types of phase morphology were observed; interconnected- and droplet-type structures indicating the spinodal decomposition and the nucleation and growth mechanism, respectively. Moreover, the multi-step liquid phase separation was observed in all alloys obviously at the free surface of the ribbons. The in-situ nanocrystalline/amorphous composite was formed in the $\mathrm{Ag}_{60} \mathrm{Cu}_{20} \mathrm{Zr}_{20}$ ribbon which resulted in a significant increase of hardness.

\section{Acknowledgements}

The authors thank S. Donath, for his technical assistance. Financial support of CNPq (Brazil), DAAD (Germany), and the Erasmus Mundus (BRIDGING THE GAP project) is gratefully appreciated.

Materialia. 2010; 58(7):2483-2491. http://dx.doi.org/10.1016/j. actamat.2009.12.034.

7. Janovszky D, Tomolya K, Sycheva A, Pekker P and Roósz A. Liquid separation in $\mathrm{Cu}-\mathrm{Zr}-\mathrm{Ag}$ ternary alloys. Journal of Alloys and Compounds. 2014; 586:S194-S198. http://dx.doi. org/10.1016/j.jallcom.2012.12.067.

8. Han J, Mattern N, Kim D and Eckert J. Phase separation and microstructure evolution of rapidly quenched $\mathrm{Gd}-\mathrm{Hf}-\mathrm{Co}-\mathrm{Al}$ alloys. Journal of Alloys and Compounds. 2011; 509S:S42-S45. http://dx.doi.org/10.1016/j.jallcom.2010.12.210.

9. Ziewiec K, Malczewski P, Gajerski R and Ziewiec A. The microstructure development in arc-melt and melt-spun $\mathrm{Fe}_{50} \mathrm{Ni}_{10} \mathrm{Cu}_{20} \mathrm{P}_{10} \mathrm{Si}_{5} \mathrm{~B}_{5}$ immiscible alloy. Journal of Non-Crystalline Solids. 2011; 357(1):73-77. http://dx.doi.org/10.1016/j. jnoncrysol.2010.10.002.

10. Park B, Chang H, Kim D, Kim W, Chattopadhyay K, Abinandanan T, et al. Phase separating bulk metallic glass: a hierarchical composite. Physical Review Letters. 2006; 96(24):245503. http:// dx.doi.org/10.1103/PhysRevLett.96.245503. PMid:16907253.

11. Kozieł T, Kedzierski Z, Zielinska-Lipiec A and Latuch J. The microstructure of melt-spun alloys with liquid miscibility gap. Journal of Physics: Conference Series. 2009; 144:012093. http://dx.doi.org/10.1088/1742-6596/144/1/012093. 
12. Tkatch V, Limanovskii A, Denisenko S and Rassolov S. The effect of the melt-spinning of processing parameters on the rate cooling. Materials Science and Engineering A. 2002; 323(12):91-96. http://dx.doi.org/10.1016/S0921-5093(01)01346-6.

13. Kuisma-Kursula P. Accuracy, precision and detection limits of SEM-WDS, SEM-EDS and PIXE in the multi-elemental analysis of medieval glass. X-Ray Spectrometry. 2000; 29(1):111-118. http:// dx.doi.org/10.1002/(SICI)1097-4539(200001/02)29:1<111::AIDXRS408>3.0.CO;2-W.

14. Brodowsky H and Schaller H-J. Relaxation and crystallization of metallic glasses. In: Brodowsky H and Schaller H-J, editors.
Thermochemistry of alloys: recent developments of experimental methods. Dordrecht: Springer Netherlands; 1989. p. 464-466.

15. Nagase T, Yokoyama A and Umakoshi Y. Multi-scale crystalline $\mathrm{Cu}$ globule dispersed Fe-based metallic glass formation by multi-step liquid phase separation. Journal of Alloys and Compounds. 2010; 494(1-2):295-300. http://dx.doi.org/10.1016/j. jallcom.2010.01.015.

16. Song K, Gargarella P, Pauly S, Ma G, Kuhn U and Eckert J. Correlation between glass-forming ability, thermal stability, and crystallization kinetics of $\mathrm{Cu}-\mathrm{Zr}-\mathrm{Ag}$ metallic glasses. Journal of Applied Physics. 2012; 112(6):063503. http://dx.doi. org/10.1063/1.4752263. 